\title{
Diaphragm dysfunction after cardiac surgery: a global approach
}

\author{
Abdallah Fayssoil ${ }^{1}$ (1) \\ Received: 30 October 2019 / Accepted: 17 November 2019 / Published online: 20 November 2019 \\ (c) Springer Nature B.V. 2019
}

\begin{abstract}
Diaphragm ultrasound is a noninvasive technique that can be used to assess diaphragm function. In cardiac surgery, the technique may help physicians during the weaning process, in addition with echocardiography after surgery.
\end{abstract}

Keywords Diaphragm · Ultrasound · Cardiac surgery

I read with great interest the paper by Antonio Tralhão et al. [1] about diaphragm dysfunction in patients after cardiac surgery. The study included 79 cardiac surgery patients with a mean age of 62 years, a mean body mass index at $26 \mathrm{~kg} /$ $\mathrm{m}^{2}$ and a mean cardiopulmonary bypass time at $107 \mathrm{~min}$. The authors reported, using ultrasound diaphragm excursion motion and diaphragm thickening fraction, a feature of diaphragm parameters at day 1 after surgery, that was reversible at day 5 after surgery [1]. All diaphragm ultrasound were done after extubation. Since diaphragm motion depend on lung volume, eventual lung hyperinflation and abdominal obesity [2], it may be useful to provide spirometric data and the eventual presence of atelectasis to clarify the results. Also, we do not know the impact of the presence of mediastinal and thoracic drain tubes at day 1 on diaphragm mobility. A diaphragm ultrasound evaluation just before and after thoracic drain tubes ablation may clarify this situation. Finally, catecholamines were used in $28 \%$ of patients. Since diaphragm function can be affected in heart failure situations [3], it would be helpful to provide data in patients with left ventricular dysfunction versus patients with normal left ventricular function.

\section{Compliance with ethical standards}

Conflict of interest The author declares that he has no conflict of interest.

\section{References}

1. Tralhão A, Cavaleiro P, Arrigo M, Lopes JP, Lebrun M, RivasLasarte M, Le Pimpec-Barthes F, Latrémouille C, Achouh P, Pirracchio R, Cholley B. Early changes in diaphragmatic function evaluated using ultrasound in cardiac surgery patients: a cohort study. J Clin Monit Comput. 2019. https://doi.org/10.1007/s1087 7-019-00350-8.

2. Smargiassi A, Inchingolo R, Tagliaboschi L, Di Marco Berardino A, Valente S, Corbo GM. Ultrasonographic assessment of the diaphragm in chronic obstructive pulmonary disease patients: relationships with pulmonary function and the influence of body composition: a pilot study. Respiration. 2014;87(5):364-71.

3. Miyagi M, Kinugasa Y, Sota T, Yamada K, Ishisugi T, Hirai M, Yanagihara K, Haruki N, Matsubara K, Kato M, Yamamoto K. Diaphragm muscle dysfunction in patients with heart failure. J Card Fail. 2018;24(4):209-16.

Publisher's Note Springer Nature remains neutral with regard to jurisdictional claims in published maps and institutional affiliations.
Abdallah Fayssoil

abdallah.fayssoil@aphp.fr

1 Raymond Poincaré Hospital, APHP, Garches, France 